\title{
THERMODYNAMIC AND ACOUSTIC STUDIES ON VARIOUS BINARY LIQUID MIXTURES
}

\author{
T. Kalimulla ${ }^{1} *$, D. Das ${ }^{2}$, M. Gowrisankar ${ }^{3}$, K. Govinda Rao ${ }^{1}$ and Shaik. Babu ${ }^{1}$ \\ ${ }^{1}$ Department of Physics, Koneru Lakshmaiah Education Foundation, \\ Vaddeswaram, Guntur, AP, India \\ ${ }^{2}$ Department of Chemistry, Dinhata College, Cooch Behar Panchanan Barma University, \\ Dinhata, 736135, W. B., India \\ ${ }^{3}$ Department of Chemistry, J.K.C.C. Acharya Nagarjuna University, Guntur-522006, AP, India \\ E-mail: kalimullaforu@gmail.com
}

\begin{abstract}
Acoustical and excess thermo physical properties of 2 methylcyclohexanone with O-chloroaniline, O-toluidine explored at varying temperatures $(303.15-318.15 \mathrm{~K})$ and close gas pressure by evaluating speed of sound $(\mathrm{u})$, density $(\rho)$ and viscosity $(\eta)$ over the total vary of composition. The trend in the acoustical and excess thermo acoustic parameters exhibit the existence of hydrogen-bonded and charge transfer complexes between the binary system. The variation of the excess parameters both in sign and magnitude in the full range of composition investigated. These results were fitted to Redlich-Kister polynomial equations to estimate the binary coefficients and standard errors. The partial and excess partial molar volumes for each component at infinite dilution have been appraised and reported.
\end{abstract}

Keywords: Speed of Sound, Viscosity, Density, R-K polynomial, Partial and Excess Partial Molar Volumes.

(C)ASĀYAN. All rights reserved

\section{INTRODUCTION}

The investigation of atomic connections in blended dissolvable frameworks is of incredible noteworthiness inferable from the reasonable utilization of these frameworks in different advancements, as they furnish a wide selection of arrangements with fitting properties. The abundance thermodynamic properties of parallel fluid blends have been valuable for acquiring data on the intermolecular connections in the frameworks. The negative or positive deviations from the perfect worth rely upon the sort and degree of the cooperation between not at all like particles, just as on the organization and the temperature. ${ }^{1,2}$ Knowledge of the physico-concoction properties of non-watery paired fluid blends has importance in hypothetical and connected regions of research and such outcomes are much of the time utilized in the structure procedure (stream, mass exchange or warmth move counts) in numerous compound and modern procedures. The overabundance properties got from these physical property information mirror the physico-concoction conduct of the fluid blends concerning the arrangement structure and intermolecular collaborations between the segment particles of the mixture. ${ }^{3,4}$

This work is part of our program to give information/data for the characterization of molecular interactions between solvents in binary systems. ${ }^{5}$ The liquids were chosen for the present study on the basis of their general importance. 2-Methylcyclohexanone (2MCH) is an important compound used in the Dairy products and analogs, oil emulsions, processed fruit and vegetables, Ready-to-eat savories and snacks. It is also used in the Salts, spices, soups, sauces, salads and protein products. On the other hand, the liquids were chosen in the present study on the basis of their industrial importance. O-Chloroaniline (O-CA) is chosen as polar solvent and self associated through hydrogen bonding of their amine group. The amino group in o-chloroaniline is an electron-donor and the hydrogen atom in the $\mathrm{NH} 2$ group can also play the role of proton-acceptor centers. O-Chloroaniline is used as parent substances in the

Rasayan J. Chem., 12(4), 1909-1918(2019)

http://dx.doi.org/10.31788/RJC.2019.1245481

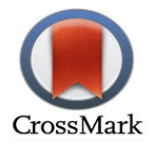


production of antioxidants, agricultural, pharmaceutical and rubber chemicals. It is also used in the manufacture of intermediate for synthetic dyes, and organic pigments especially for red color. ${ }^{6} \mathrm{O}-$ Toluidine (O-TA) may cause rupture or enhance self-association in pyridine or substituted O-Toluidine which in turn would change their respective topology. ${ }^{7}$

In the present study, our focus is on the study of liquid mixtures of substituted O-CA and O-TA with 2methylcyclohexanone because there have been a few studies on these mixtures. ${ }^{8}$ It is expected that there will be a significant degree of $\mathrm{H}$-bonding in these binary mixtures we report the densities, speeds of sound and viscosities for two binary systems (2MCH with O-CA and O-TA) at $\mathrm{T}=303.15-318.15 \mathrm{~K}$ ambient atmospheric pressure. The experimental data has been used to compute the excess parameters, partial molar volumes and FTIR studies. The results are used to qualitatively discuss specific interactions between unlike molecules.

\section{Materials}

\section{EXPERIMENTAL}

Chemicals used in the present study are 2-methylcyclohexanone (Sigma-Aldrich), O-Chloroaniline and O-Toluidine (Sigma-Aldrich). These chemicals were purchased from S.D. Fine Chemicals Ltd. These chemicals were further purified by standard methods. ${ }^{9}{ }^{10}$ like distillation and fractional distillation under reduced pressure, and only the middle fractions were collected. Before use, the chemicals were stored over $0.4 \mathrm{~nm}$ molecular sieves for about $72 \mathrm{~h}$ to remove water and gas. The purity of the liquid samples was checked by gas chromatography. The water contents were determined by the Karl-Fischer method.

\section{Method}

All liquid mixtures were prepared by weighing a number of pure liquids in an electronic balance with a precision of $\pm 0.1 \mathrm{~kg} \mathrm{~m}^{-3}$. The binary mixtures were prepared just before use. The uncertainty in mole fraction was estimated to be less than \pm 0.0001 . The speed of sound was measured with an ultrasonic interferometer (Mittal Enterprises, Delhi, India) working at $2 \mathrm{MHz}$ frequency and 303.15- 318.15 K temperature. The uncertainty in the speed of sound was found to be $\pm 0.1 \mathrm{~ms}^{-1}$. An electronically digital operated constant temperature water bath has been used to circulate water through the double-walled measuring cell made up of steel containing the experimental solution at the desired temperature.

The viscosities were measured with Ostwald viscometer. The viscometer was calibrated at each temperature using distilled water. The uncertainty in viscosity measurement is up to $0.001 \mathrm{mPa}$. The flow time has been measured after the attainment of bath temperature by each mixture. The flow measurements were made with an electronic stopwatch with precision of $0.01 \mathrm{~s}$. For all pure components and mixtures, 3-4 readings were taken, and the average of these values was used in all the calculations.

The densities of the pure compounds and their mixtures were determined accurately using $10 \mathrm{~mL}$ specific gravity bottles in digital electronic balance with an uncertainty of $\pm 0.1 \mathrm{~kg} \mathrm{~m}^{-3}$. The average uncertainty in the measured density was $\pm 0.001 \mathrm{~kg} \mathrm{~m}^{-3}$.

\section{Theoretical Details}

The values of experimentally determined density, viscosity and speed of sound for the liquid mixtures of 2-methylcyclohexanone with O-Chloroaniline and O-Toluidine at $303.15 \mathrm{~K}-318.15 \mathrm{~K}$ over the entire composition range are given in Table-1. The experimentally determined values of speed of sound, density and viscosity, various thermodynamic parameters like excess isentropic compressibility $\left(K_{s}^{E}\right)$, excess Enthalpy $\left(H^{E}\right)$, excess molar volume $\left(V^{E}\right)$, excess Gibb's free energy $\left(\Delta G^{*}\right)$ and excess free length $\left(L_{f}{ }^{E}\right)$ were calculated. The excess values of isentropic compressibility, $K_{s}^{E}$ were calculated as follows;

Table-1: Comparison of Experimental Densities ( $\rho)$, Viscosities $(\eta)$ and Speed of Sound (U) of Pure Liquids with Literature Values.

\begin{tabular}{c|c|c|c|c|c|c|c}
\hline \multirow{2}{*}{ Liquid } & $\begin{array}{c}\text { Temp } \\
\mathrm{T}(\mathrm{K})\end{array}$ & \multicolumn{2}{|c|}{$\begin{array}{c}\text { Density }(\rho) \\
\mathrm{kg} \mathrm{m}^{3}\end{array}$} & \multicolumn{2}{c|}{$\begin{array}{c}\text { Viscosity }(\eta) \\
\mathrm{mPa} . \mathrm{S}\end{array}$} & \multicolumn{2}{c}{$\begin{array}{c}\text { Speed of sound } \\
(\mathrm{U}) \mathrm{m} . \mathrm{s}-1\end{array}$} \\
\hline & & $\mathrm{expt}$ & Lit & expt & Lit & expt & Lit \\
\hline \multirow{2}{*}{$\begin{array}{c}\text { 2-Methylcyclo } \\
\text { hexanone }\end{array}$} & 303.15 & 0.9196 & $0.9195^{\mathrm{a}}$ & 2.2241 & $2.2242^{\mathrm{a}}$ & 1345.20 & $1344.6^{\mathrm{a}}$ \\
\cline { 2 - 8 } & 308.15 & 0.9125 & --- & 2.1739 & --- & 1338.53 & --- \\
\hline
\end{tabular}


RASĀYAN J. Chem.

Vol. 12 | No. 4 |1909 - 1918| October - December | 2019

\begin{tabular}{c|c|c|c|c|c|c|c}
\hline & 313.15 & 0.9110 & --- & 2.0238 & --- & 1330.27 & --- \\
\cline { 2 - 8 } & 318.15 & 0.9086 & --- & 2.0172 & --- & 1320.08 & --- \\
\hline \multirow{3}{*}{ O-Chloroaniline } & 303.15 & 1.2026 & $1.2026^{\mathrm{b}}$ & 3.8262 & $3.8256^{\mathrm{b}}$ & 1470.20 & $1469.6^{\mathrm{b}}$ \\
\cline { 2 - 8 } & 308.15 & 1.1979 & $1.9802^{\mathrm{b}}$ & 3.4219 & $3.4122^{\mathrm{b}}$ & 1454.5 & $1453.3^{\mathrm{b}}$ \\
\cline { 2 - 8 } & 313.15 & 1.1928 & $1.1930^{\mathrm{b}}$ & 3.0634 & $3.0602^{\mathrm{b}}$ & 1436.4 & $1435.2^{\mathrm{b}}$ \\
\cline { 2 - 8 } & 318.15 & 1.1879 & $1.1884^{\mathrm{b}}$ & 2.7708 & $2.7621^{\mathrm{b}}$ & 1419.8 & $1418.9^{\mathrm{b}}$ \\
\hline \multirow{3}{*}{ O-Toluidine } & 303.15 & 0.9902 & $0.9902^{\mathrm{c}}$ & 3.4521 & --- & 1577.79 & $1577.82^{\mathrm{c}}$ \\
\cline { 2 - 8 } & 308.15 & 0.9860 & $0.9860^{\mathrm{c}}$ & 3.1254 & --- & 1558.38 & $1588.38^{\mathrm{c}}$ \\
\cline { 2 - 8 } & 313.15 & 0.9816 & --- & 2.8643 & --- & 1539.62 & --- \\
\cline { 2 - 8 } & 318.15 & 0.9746 & --- & 2.4217 & --- & 1518.34 & -- \\
\hline
\end{tabular}

a Gowrisankar et al. ${ }^{4}$,

b D. Ubagaramary et al. ${ }^{6}$

c Neeti saini et al. ${ }^{7,11}$

$$
K_{s}^{E}=K_{s}-K_{s}^{i d}
$$

Where, $K_{s}^{E}$ is its excess value, $K_{s}^{\text {id }}$ is the ideal isentropic compressibility value and $K_{s}$ represents the calculated value of isentropic compressibility for the mixture. $K_{s}^{i d}$ for an ideal mixture was calculated from the relation recommended by Kiyohara and Benson. ${ }^{12}$ Benson and Kiyohara. ${ }^{13}$ and Douheret et al. ${ }^{14}$

$$
\mathrm{K}_{\mathrm{s}}^{\mathrm{id}}=\sum \phi_{i}\left\{K_{s, i}^{\circ}+\frac{T V_{i}^{\circ}\left(\alpha_{i}^{\circ}\right)^{2}}{C_{p, i}^{\circ}}\right\}-\mathrm{T}\left(\sum X_{i} V_{i}^{\circ}\right)\left\lceil\frac{\sum \phi_{i} \alpha_{i}^{\circ}}{\sum X_{i} C_{p, i}^{\circ}}\right\rceil
$$

In which $K_{s, i}^{\circ}, V_{0}^{i}, \alpha_{i}^{o}, C_{p, j}^{o}$ are the isentropic compressibility, molar volume, isobaric thermal expansion coefficient and molar isobaric heat capacity of pure component $i, T$ represents temperature, $\phi_{i}$ is the volume fraction and $x_{i}$ represents the mole fraction of $i$ in the mixture.

Excess enthalpy $H^{E}$ was calculated from usual relation,

$$
\mathrm{H}^{\mathrm{E}}=\mathrm{H}-\left(\mathrm{X}_{1} \mathrm{H}_{1}+\mathrm{X}_{2} \mathrm{H}_{2}\right)
$$

Where $H$ represents the calculated value of enthalpy for the mixture and $H_{1}, H_{2}$ represents enthalpy of pure components 1 and 2 , respectively.

The density values have been used to calculate the excess volumes, $\mathrm{V}^{\mathrm{E}}$, using the following equation,

$$
\mathrm{V}^{\mathrm{E}}=\frac{X_{1} M_{1}+X_{2} M_{2}}{\rho}-\left(\frac{X_{1} M_{1}}{\rho_{1}}+\frac{X_{2} M_{2}}{\rho_{2}}\right)
$$

Where, $\rho$ is the density of the mixture and $X_{1}, M_{1}$, and $X_{2}, M_{2}$, and $\rho_{1}, \rho_{2}$ are the mole fraction, molar mass, and density of pure components 1 and 2, respectively.

Excess Gibbs free energy of activation $\Delta \mathrm{G}^{* \mathrm{E}}$ was calculated as follows,

$$
\Delta \mathrm{G}^{* \mathrm{E}}=\mathrm{RT}\left[\ln \left(\frac{\eta \mathrm{V}}{\eta_{2} \mathrm{~V}_{2}}\right)-\mathrm{X}_{1} \ln \left(\frac{\eta_{1} \mathrm{~V}_{1}}{\eta_{2} \mathrm{~V}_{2}}\right)\right]
$$

Where, $R$ represents gas constant, $T$ is absolute temperature, $\eta$ is the viscosity of the mixture and $\eta_{1}, \eta_{2}$ are the viscosities of the pure compounds, $V_{m}$ is the molar volume of the mixture and $V_{l}, V_{2}$ are the volumes of the $R$.

The excess values of the free length $\mathrm{L}_{\mathrm{f}}^{\mathrm{E}}$ were calculated by using the expression,

$$
\mathrm{L}_{\mathrm{f}}^{\mathrm{E}}=\mathrm{L}_{\mathrm{f}}-\mathrm{K}_{\mathrm{T}}\left(\mathrm{K}_{\mathrm{s}}^{\mathrm{id}}\right)^{1 / 2}
$$

Where $L_{f}$ represents the calculated value for the mixture and $K_{T}$ represents a temperature-dependent constant whose value is $K_{T}=(91.368+0.3565 T) X 10-8$.

The conventional smooth curve fitting strategy for excess properties of binary mixture involves RedlichKister. ${ }^{15}$ polynomial non-linear regression,

$$
\mathrm{Y}^{\mathrm{E}}=\mathrm{X}_{1}\left(1-\mathrm{X}_{1}\right) \sum_{i=1}^{n} A_{i}\left(2 x_{1}-1\right)
$$

Where $\mathrm{Y}^{\mathrm{E}}=\mathrm{K}_{\mathrm{s}}^{\mathrm{E}}, \mathrm{V}^{\mathrm{E}}, \Delta \mathrm{G}^{* \mathrm{E}}, \mathrm{H}^{\mathrm{E}}$. The values of coefficient $\mathrm{A}_{\mathrm{i}}$ were determined by a regression analysis based on the least-squares method.

The standard deviation $(\sigma)$ was calculated using the relation,

$$
\sigma\left(\mathrm{Y}^{\mathrm{E}}\right)=\left[\sum\left(Y_{\text {obs }}^{E} Y_{\text {cal }}^{E}\right)^{2} / \mathrm{n}-\mathrm{m}\right]^{1 / 2}
$$


Where $n, m$ represents the number of experimental points and adjustable parameters.

\section{RESULTS AND DISCUSSION}

The experimental values of density, viscosity and speed of sound in case of all the liquid mixtures understudy over the entire range of composition and at $303.15-318.15 \mathrm{~K}$ are given in Table- 1 . From this available data of speed of sound, density and viscosity, values of excess isentropic compressibility $\left(\mathrm{K}_{\mathrm{s}}^{\mathrm{E}}\right)$, excess molar volume $\left(V^{\mathrm{E}}\right)$, excess free length $\left(\mathrm{L}_{\mathrm{f}}^{\mathrm{E}}\right)$, excess Gibbs free energy of activation $\left(\Delta \mathrm{G}^{*} \mathrm{E}\right)$ and excess Enthalpy $\left(\mathrm{H}^{\mathrm{E}}\right)$, were calculated. These excess parameters were plotted against mole fraction of $2 \mathrm{MCH}$ with O-CA and O-TA over the entire mole fraction range and at $303.15-318.15 \mathrm{~K}$. The plots are shown in Figs.-1 to 5. The excess parameters of isentropic compressibility $\left(\mathrm{K}_{\mathrm{s}}^{\mathrm{E}}\right)$, molar volume $\left(\mathrm{V}^{\mathrm{E}}\right)$, free length $\left(\mathrm{L}_{\mathrm{f}}^{\mathrm{E}}\right)$, Gibbs free energy of activation $\left(\Delta \mathrm{G}^{* \mathrm{E}}\right)$ and Enthalpy $\left(\mathrm{H}^{\mathrm{E}}\right)$, are fitted to the Redlich-Kister type polynomial equation and the coefficients $A_{i}$ evaluated by the method of least squares, along with standard deviation $(\sigma)$ are given in Table- $2 .{ }^{16}$ The deviations observed in the excess parameters indicate the strength of interactions present between the component molecules of the binary mixtures under study. The variations in these excess parameters may be the result of contributions from several effects such as (a) The Specific forces that exist between the molecules, like the charge transfer complexes and existence of hydrogen bonds result in the negative excess values. (b) Physical interatomic forces. (c) The structural contribution arising from the geometrical fitting of one component into the other because of the differences in the size and shape of the component molecules. ${ }^{17}$ Figures- $1 \mathrm{a}$ and $1 \mathrm{~b}$ shows the excess isentropic compressibility $\mathrm{K}_{\mathrm{s}}^{\mathrm{E}}$ for the binary liquid mixtures of $2 \mathrm{MCH}$ with O-CA, O-TA respectively, over the entire mole fraction range and at different temperatures $\mathrm{T}=(303.15-318.15) \mathrm{K}$. The excess isentropic compressibility $\left(\mathrm{K}_{\mathrm{s}}^{\mathrm{E}}\right)$ for the liquid mixtures under study is as shown in Fig.-1a and b. It can be observed that the $\mathrm{K}_{\mathrm{s}}^{\mathrm{E}}$ values are positive in case of $2 \mathrm{MCH}+\mathrm{O}-\mathrm{TA}$ over the entire mole fraction range indicating the presence of weak interactions in these mixtures and also that the molecules are loosely packed in the mixtures due to their shape and size. ${ }^{18} \mathrm{~K}_{\mathrm{s}}^{\mathrm{E}}$ values are negative in case of $2 \mathrm{MCH}+\mathrm{O}-\mathrm{CA}$ over the entire mole fraction range. The negative values of $\mathrm{K}_{\mathrm{s}}^{\mathrm{E}}$ are of the sign of excess isentropic compressibility plays a vital role in assessing the compactness due to molecular interaction in liquid mixtures through charge transfer, dipole-dipole interactions, and dipole induced dipole interactions interstitial accommodation and orientation ordering which leads to more compact structure making, which enhances excess isentropic compressibility to have negative values as suggested by Fort and Moore. ${ }^{19}$

The variation of excess molar volume $\left(\mathrm{V}^{\mathrm{E}}\right)$, with respect to mole fraction, $\mathrm{x}_{1}$, is given in Fig. $-2 \mathrm{a}$, and $\mathrm{b}$ over the entire composition range and at different $\mathrm{T}=(303.15-318.15) \mathrm{K}$. The strength of the intermolecular interactions in binary liquid mixtures can be explained using the sign and magnitude of the $\mathrm{V}^{\mathrm{E}}$ values. The negative values of $\mathrm{V}^{\mathrm{E}}$ are due to strong specific interactions like the formation of H-bond, association through weaker physical forces and accommodation of one component molecules into the voids in the network of the other component molecules. So in the present study we observed that the behavior of $\mathrm{V}^{\mathrm{E}}$ can be ascribed to the formation of $\mathrm{H}$-bond, disruption of alcohol self-associations and the structural characteristics like geometrical fitting of one component into the other as a result of the increase in difference of size and shape of the component molecules. It is clear from Fig.-2 that the negative values of $\mathrm{V}^{\mathrm{E}}$ are in $2 \mathrm{MCH}+\mathrm{O}-\mathrm{CA}$. The expansion in molar volume can be attributed to the presence of weak intermolecular forces of attraction. ${ }^{20}$ Similar results were reported by Garci'a et al. ${ }^{21}$

The negative values of $\mathrm{V}^{\mathrm{E}}$ indicate that there is more compact packing of the molecules which implies that the molecular interactions are strong, whereas in $2 \mathrm{MCH}+\mathrm{O}-\mathrm{TA}$, the positive values indicate a loose packing of molecules in the binary mixture compared to those in the pure component. Similar results were observed by earlier workes. ${ }^{22,23}$

Figure-3a and $b$ show the $\mathrm{L}_{\mathrm{f}}^{\mathrm{E}}$ values have negative suggest that existence of strong intermolecular interaction through hydrogen bonding between the component molecules in $2 \mathrm{MCH}+\mathrm{O}-\mathrm{CA}$. The positive values indicate the specific interactions are present between unlike molecules between the component molecules of the $2 \mathrm{MCH}+\mathrm{O}-\mathrm{TA}$ liquid mixtures under study. ${ }^{24}$

Figures-4a and $b$ represent the excess Gibb's free energy of activation $\left(\Delta \mathrm{G}^{*}{ }^{\mathrm{E}}\right)$ with respect to mole fraction $\mathrm{x}_{1}$, over the entire composition range and at $\mathrm{T}=\left(303.15-318.15\right.$,) $\mathrm{K}$. The $\Delta \mathrm{G}^{* \mathrm{E}}$ are in $2 \mathrm{MCH}+\mathrm{O}-$ CA, O-TA having negative values. The expansion in molar volume can be attributed to the presence of 
RASĀYAN J. Chem.

Vol. 12 | No. 4 |1909 - 1918| October - December | 2019

weak intermolecular forces of attraction. Similar results were observed by earlier workers. ${ }^{25}$ From Fig.-5a and $\mathrm{b}$ it is clear that the excess values of Enthalpy $\left(\mathrm{H}^{\mathrm{E}}\right)$ are positive with respect to the mole fraction $\mathrm{x}_{1}$, over the entire composition range and at $\mathrm{T}=303.15-318.15 \mathrm{~K}$. The positive values of $\mathrm{H}^{\mathrm{E}}$ insist the fact that there are strong specific interactions between unlike molecules in these liquid mixtures. The positive $\mathrm{H}^{\mathrm{E}}$ values also suggest the existence of intermolecular hydrogen bond and the breaking of associated structures in case of $2 \mathrm{MCH}$ with O-CA, O-TA. ${ }^{26}$
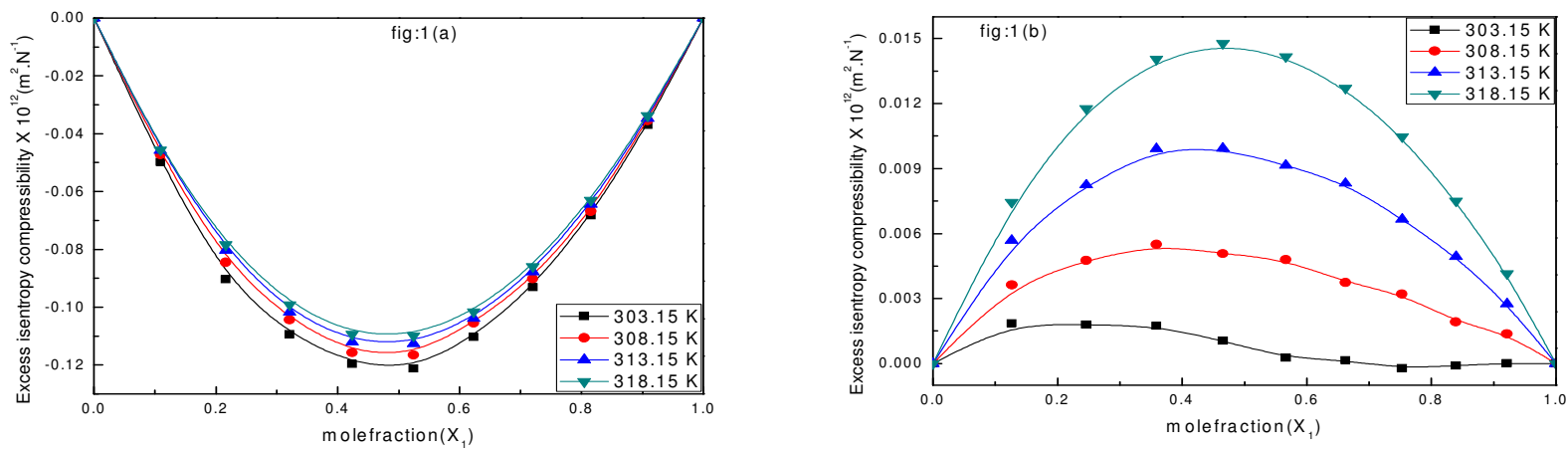

Fig.-1: Variation of Excess Isentropic Compressibility $\left(\mathrm{K}_{\mathrm{s}}^{\mathrm{E}}\right)$ with Mole Fraction $\left(\mathrm{x}_{1}\right)$ in the Binary Liquid Mixtures of $2 \mathrm{MCH}$ with $\mathrm{O}-\mathrm{CA}, \mathrm{O}-\mathrm{TA}$ at Various Temperatures.
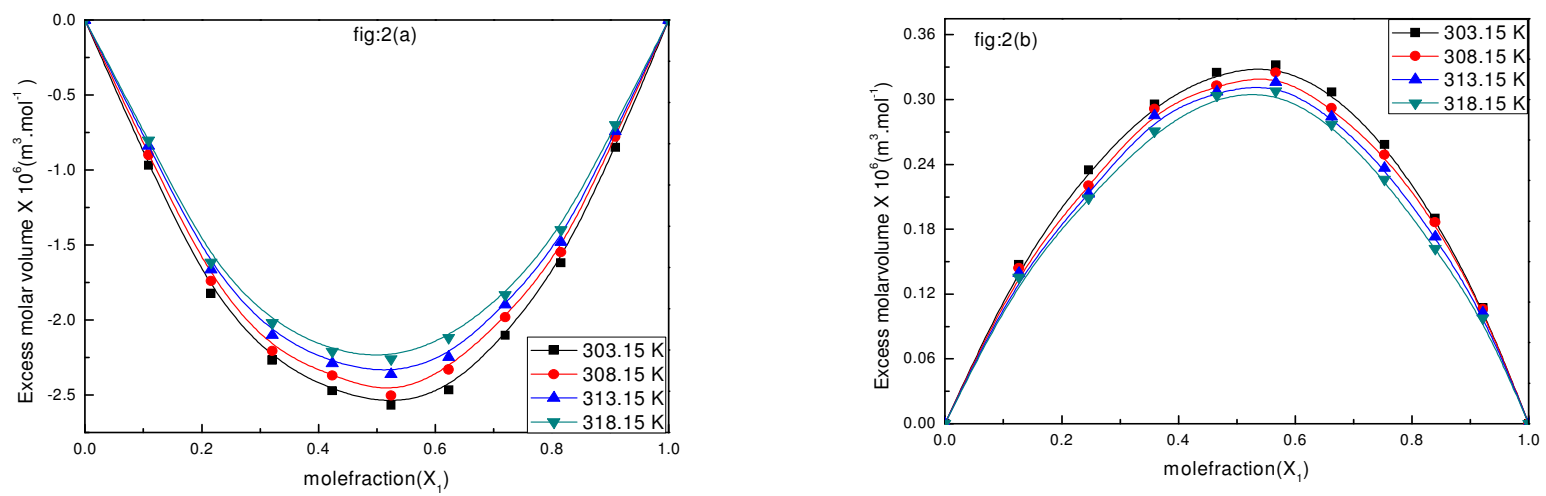

Fig.-2: Variation of Excess Molar Volume $\left(\mathrm{V}^{\mathrm{E}}\right)$ with Mole Fraction $\left(\mathrm{x}_{1}\right)$ in the Binary Liquid Mixtures of 2MCH with O-CA, O-TA at Various Temperatures.
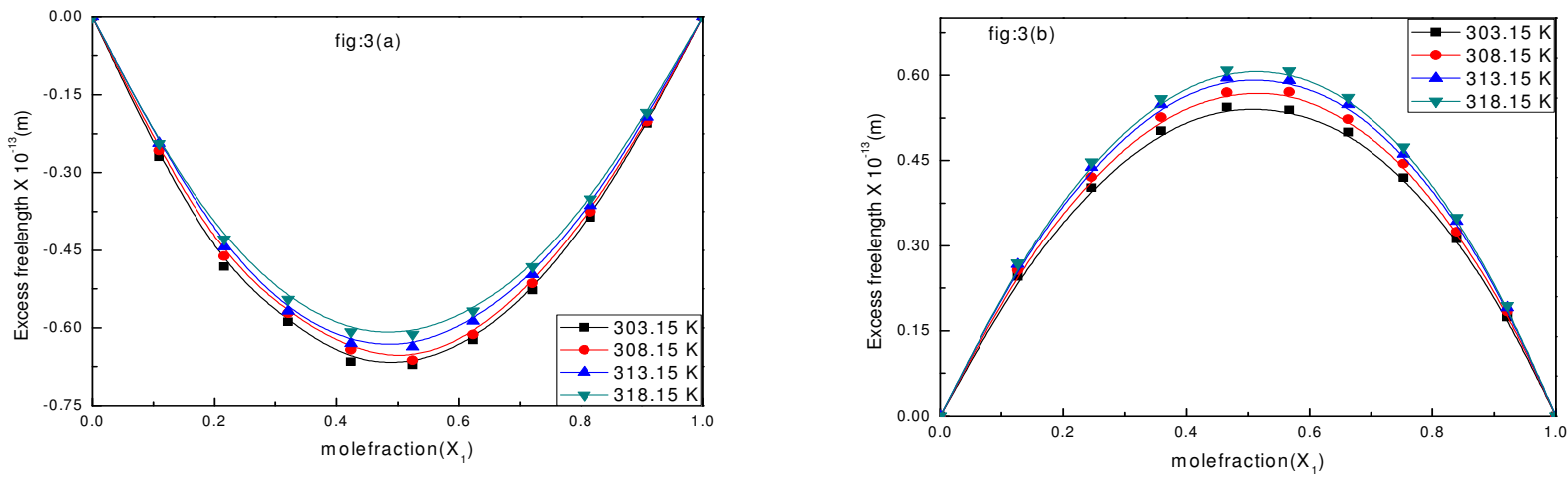

Fig.-3: Variation of Excess Free Length $\left(\mathrm{L}_{\mathrm{f}}^{\mathrm{E}}\right)$ with Mole Fraction $\left(\mathrm{x}_{1}\right)$ in the Binary Liquid Mixtures of $2 \mathrm{MCH}$ with O-CA, O-TA at Various Temperatures. 
RASĀYAN J. Chem.

Vol. 12 | No. 4 |1909 - 1918| October - December | 2019
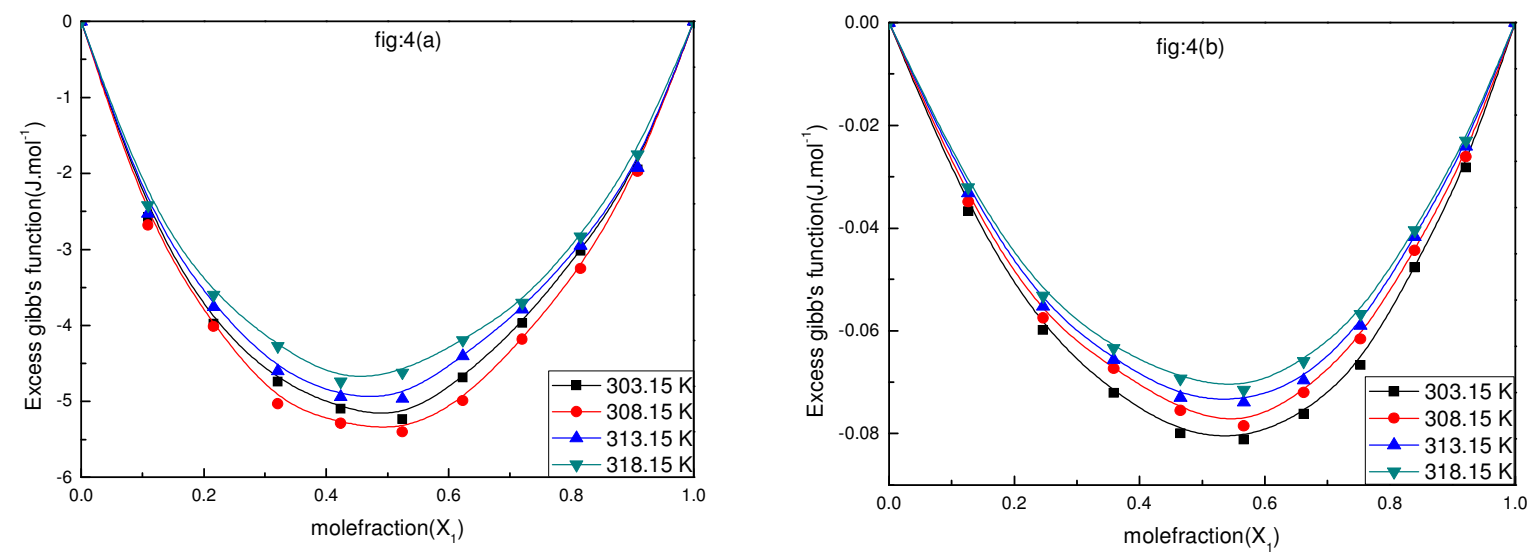

Fig.-4: Variation of Excess Gibb's Function $\left(\Delta \mathrm{G}^{\mathrm{E}}\right)$ with Mole Fraction $\left(\mathrm{x}_{1}\right)$ in the Binary Liquid Mixtures of $2 \mathrm{MCH}$ with O-CA, O-TA at Various Temperatures.
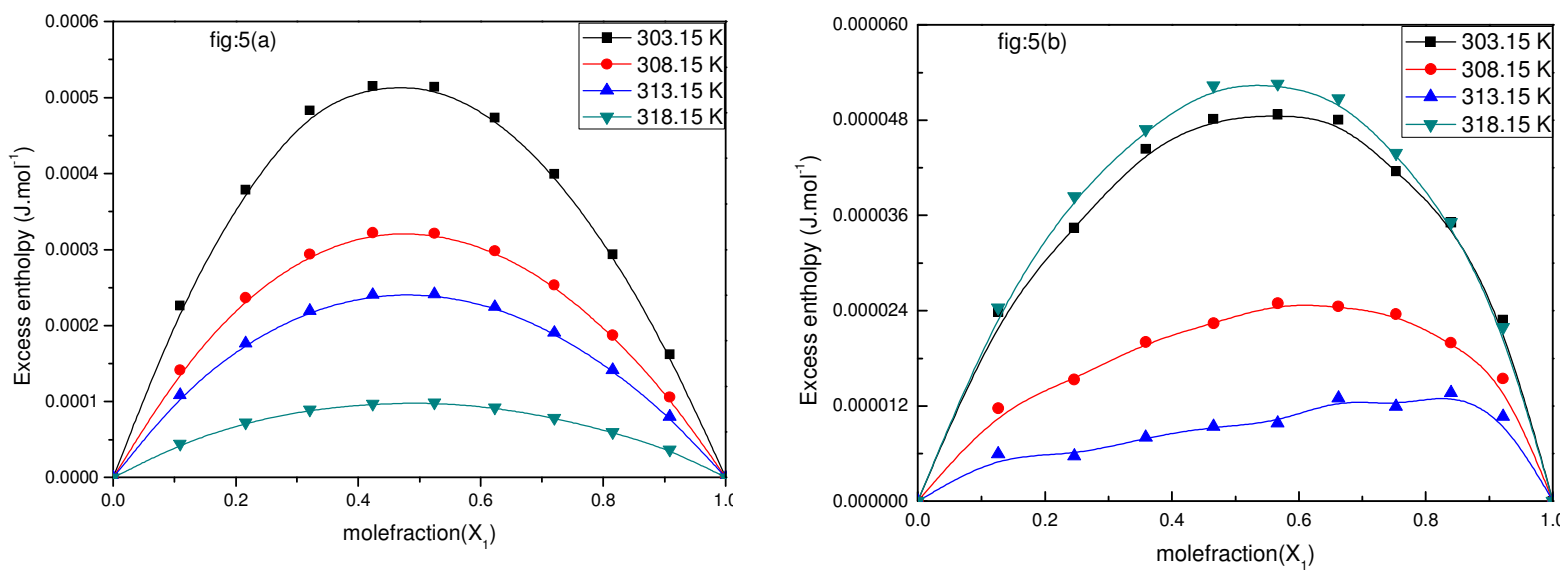

Fig.-5: Variation of Excess Enthalpy $\left(\mathrm{H}^{\mathrm{E}}\right)$ with Mole Fraction $\left(\mathrm{x}_{1}\right)$ in the Binary Liquid Mixtures of $2 \mathrm{MCH}$ with O-CA, O-TA at Various Temperatures.

The variations in these above excess parameters with mole fraction and temperature predict the presence of hydrogen bonding between the compounds in $2 \mathrm{MCH}+\mathrm{O}-\mathrm{CA}$. The excess parameters calculated in the present study correlate with one another and at the same time, each parameter supports the formation of hydrogen bonding in these binary liquid mixtures. But in case of $2 \mathrm{MCH}+\mathrm{O}$-TA presence of weak intermolecular forces of attraction.

The existing molecular interactions in the systems are well reflected in the properties of partial molar volumes. The partial molar volumes $V_{m, 1}$ of component 1 and $V_{m, 2}$ of component 2 in the mixtures over the entire composition range have been calculated by using the following relations:

$$
\begin{gathered}
V_{m, 1}=V_{m}{ }^{E}+V_{1}{ }^{*}+x_{2}\left(\frac{\partial V_{\mathrm{m}}^{\mathrm{E}}}{\partial \mathrm{x}}\right)_{T, P,} \\
V_{m, 2}=V_{m}{ }^{E}+V_{2}{ }^{*}+x_{2}\left(\frac{\partial V_{\mathrm{m}}^{\mathrm{E}}}{\partial \mathrm{x}}\right)_{T, P,}
\end{gathered}
$$

Where $V^{*}{ }_{1}$ and $V^{*}{ }_{2}$ are the molar volumes of the pure components of (2MCH with O-CA,O-TA) respectively. The derivates in the above equations are obtained by differentiating Redlich-Kister equation (7) which leads to the following equations for $V_{m, 1}$ and $V_{m, 2}$ : 
RASĀYAN J. Chem.

Vol. 12 | No. 4 |1909 - 1918| October - December | 2019

$$
\begin{aligned}
& V_{m, 1}=V_{1}{ }^{*}+x_{2}{ }^{2} \sum_{i=0}^{j} \mathrm{~A}_{i}\left(x_{2}-x_{1}\right)^{i}-2 x_{1} x_{2}^{2} \sum_{i=1}^{j} \mathrm{~A}_{i}\left(x_{2}-x_{1}\right)^{i^{-1},} \\
& V_{m, 2}=V_{2}{ }^{*}+x_{1}{ }^{2} \sum_{i=0}^{j} \mathrm{~A}_{i}\left(x_{2}-x_{1}\right)^{i}-2 x_{1} x_{2}{ }^{2} \sum_{i=1}^{j} \mathrm{~A}_{i}\left(x_{2}-x_{1}\right)^{i^{-1}},
\end{aligned}
$$

Using the above equations, $V^{E}{ }_{m, 1}, V^{E}{ }_{m, 2}$ have been calculated using,

$$
\begin{gathered}
V^{\mathrm{E}}{ }_{m, 1}=V_{m, 1}-V_{l}{ }^{*}, \\
V^{\mathrm{E}}{ }_{m, 2}=V_{m, 2}-V_{2}{ }^{*},
\end{gathered}
$$

The values of $V_{m, 1}$ and $V_{m, 2}$ for both the components in the mixtures are less than their respective molar volumes in the pure state; that is, an expansion of volume takes place on mixing 2MCH with O-CA,O-

\begin{tabular}{|c|c|c|c|c|c|c|}
\hline Parameter & $\begin{array}{c}\text { Temperature } \\
(\mathrm{K})\end{array}$ & A0 & A1 & $\mathrm{A} 2$ & A3 & $\sigma$ \\
\hline \multicolumn{7}{|c|}{ 2MCH + O-Chloroaniline } \\
\hline \multirow{4}{*}{$10^{12} \mathrm{~K}_{\mathrm{S}}^{\mathrm{E}} /\left(\mathrm{m}^{2} \cdot \mathrm{N}^{-1}\right)$} & 303.15 & -0.4853 & 0.0605 & -0.0054 & -0.0143 & 0.0013 \\
\hline & 308.15 & -0.4665 & 0.0513 & 0.0025 & -0.0222 & 0.0010 \\
\hline & 313.15 & -0.4535 & 0.0419 & 0.0094 & -0.0134 & 0.0002 \\
\hline & 318.15 & -0.4425 & 0.0356 & 0.0041 & 0.0047 & 0.0001 \\
\hline \multirow{4}{*}{$10^{6} \mathrm{~V}^{\mathrm{E}} /\left(\mathrm{m}^{3} \cdot \mathrm{mol}^{-1}\right)$} & 303.15 & -10.3307 & -0.1509 & -0.4226 & 0.1629 & 0.0414 \\
\hline & 308.15 & -9.9633 & 0.2012 & 0.1085 & -0.4949 & 0.0507 \\
\hline & 313.15 & -9.5355 & 0.2000 & 0.2215 & -0.6389 & 0.0477 \\
\hline & 318.15 & -9.1378 & 0.4085 & 0.2222 & -0.8609 & 0.0472 \\
\hline \multirow{4}{*}{$10^{13} \mathrm{~L}_{\mathrm{f}}^{\mathrm{E}} /(\mathrm{m})$} & 303.15 & -2.6965 & 0.1293 & 0.0479 & 0.1339 & 0.0060 \\
\hline & 308.15 & -2.6374 & 0.0825 & 0.1263 & 0.1471 & 0.0057 \\
\hline & 313.15 & -2.5636 & 0.1965 & 0.1787 & -0.1372 & 0.0030 \\
\hline & 318.15 & -2.4674 & 0.1375 & 0.1220 & 0.0597 & 0.0021 \\
\hline \multirow{4}{*}{$\Delta \mathrm{G}^{\mathrm{E}} /\left(\mathrm{J} \cdot \mathrm{mol}^{-1}\right)$} & 303.15 & -18.7391 & -2.7516 & -7.0665 & 10.1421 & 0.3853 \\
\hline & 308.15 & -21.2560 & 3.1104 & -5.1565 & -1.0211 & 0.1040 \\
\hline & 313.15 & -20.3096 & 4.7459 & -3.3951 & -7.7833 & 0.0677 \\
\hline & 318.15 & -19.3548 & 2.4926 & -6.0194 & 0.3575 & 0.0920 \\
\hline \multirow{4}{*}{$\mathrm{H}^{\mathrm{E}} /\left(\mathrm{J} \cdot \mathrm{mol}^{-1}\right)$} & 303.15 & 0.0020 & -0.0002 & 0.0000 & 0.0000 & 0.0000 \\
\hline & 308.15 & 0.0013 & -0.0001 & 0.0001 & 0.0001 & 0.0000 \\
\hline & 313.15 & 0.0010 & -0.0001 & 0.0001 & 0.0000 & 0.0000 \\
\hline & 318.15 & 0.0004 & 0.0000 & 0.0001 & 0.0000 & 0.0000 \\
\hline \multicolumn{7}{|c|}{ 2MCH + O-Toluidine } \\
\hline \multirow{4}{*}{$10^{12} \mathrm{~K}_{\mathrm{S}}^{\mathrm{E}} /\left(\mathrm{m}^{2} \cdot \mathrm{N}^{-1}\right)$} & 303.15 & 0.0031 & -0.0117 & 0.0079 & 0.0013 & 0.0001 \\
\hline & 308.15 & 0.0200 & -0.0098 & 0.0068 & -0.0011 & 0.0002 \\
\hline & 313.15 & 0.0390 & -0.0098 & 0.0081 & 0.0018 & 0.0001 \\
\hline & 318.15 & 0.0586 & -0.0074 & 0.0052 & 0.0004 & 0.0000 \\
\hline \multirow{4}{*}{$10^{6} \mathrm{~V}^{\mathrm{E}} /\left(\mathrm{m}^{3} \cdot \mathrm{mol}^{-1}\right)$} & 303.15 & 1.3179 & 0.1557 & 0.0923 & -0.1358 & 0.0025 \\
\hline & 308.15 & 1.2756 & 0.1308 & 0.0799 & -0.0555 & 0.0060 \\
\hline & 313.15 & 1.2476 & 0.1011 & 0.0076 & -0.0418 & 0.0067 \\
\hline & 318.15 & 1.2157 & 0.1107 & -0.0368 & -0.1242 & 0.0066 \\
\hline \multirow{4}{*}{$10^{13} \mathrm{~L}_{\mathrm{f}}^{\mathrm{E}} /(\mathrm{m})$} & 303.15 & 2.1870 & 0.0740 & 0.1514 & 0.0349 & 0.0018 \\
\hline & 308.15 & 2.2986 & 0.0993 & 0.1406 & 0.0077 & 0.0027 \\
\hline & 313.15 & 2.3950 & 0.1000 & 0.1582 & 0.0413 & 0.0019 \\
\hline & 318.15 & 2.4540 & 0.1238 & 0.1266 & 0.0217 & 0.0011 \\
\hline \multirow[b]{2}{*}{$\Delta \mathrm{G}^{\mathrm{E}} /\left(\mathrm{J} \cdot \mathrm{mol}^{-1}\right)$} & 303.15 & -0.3235 & -0.0425 & -0.0506 & 0.0330 & 0.0008 \\
\hline & 308.15 & -0.3073 & -0.0424 & -0.0398 & 0.0511 & 0.0012 \\
\hline
\end{tabular}
TA. These results also support the observed negative values of $V^{E}$ in O-CA and positive in O-TA.

Table-2: Coefficients of Redlich-Kister equation and Standard Deviations $(\sigma)$ for $2 \mathrm{MCH}$ with O-CA and O-TA at $\mathrm{T}=303.15-318.15 \mathrm{~K}$. 
RASĀYAN J. Chem.

Vol. 12 | No. 4 |1909 - 1918| October - December | 2019

\begin{tabular}{c|c|c|c|c|c|c}
\hline & 313.15 & -0.2956 & -0.0355 & -0.0301 & 0.0450 & 0.0008 \\
\cline { 2 - 7 } & 318.15 & -2.8930 & 1.5517 & -1.0190 & 0.8137 & 0.0024 \\
\hline \multirow{3}{*}{$\mathrm{H}^{\mathrm{E}} /\left(\mathrm{J}^{\mathrm{m}} \mathrm{mol}^{-1}\right)$} & 303.15 & 0.0000 & 0.0000 & 0.0000 & 0.0000 & 0.0000 \\
\cline { 2 - 7 } & 308.15 & 0.0000 & 0.0000 & 0.0001 & 0.0000 & 0.0000 \\
\cline { 2 - 7 } & 313.15 & 0.0000 & 0.0000 & 0.0001 & 0.0000 & 0.0000 \\
\cline { 2 - 7 } & 318.15 & 0.0000 & 0.0000 & 0.0001 & 0.0000 & 0.0000 \\
\hline
\end{tabular}
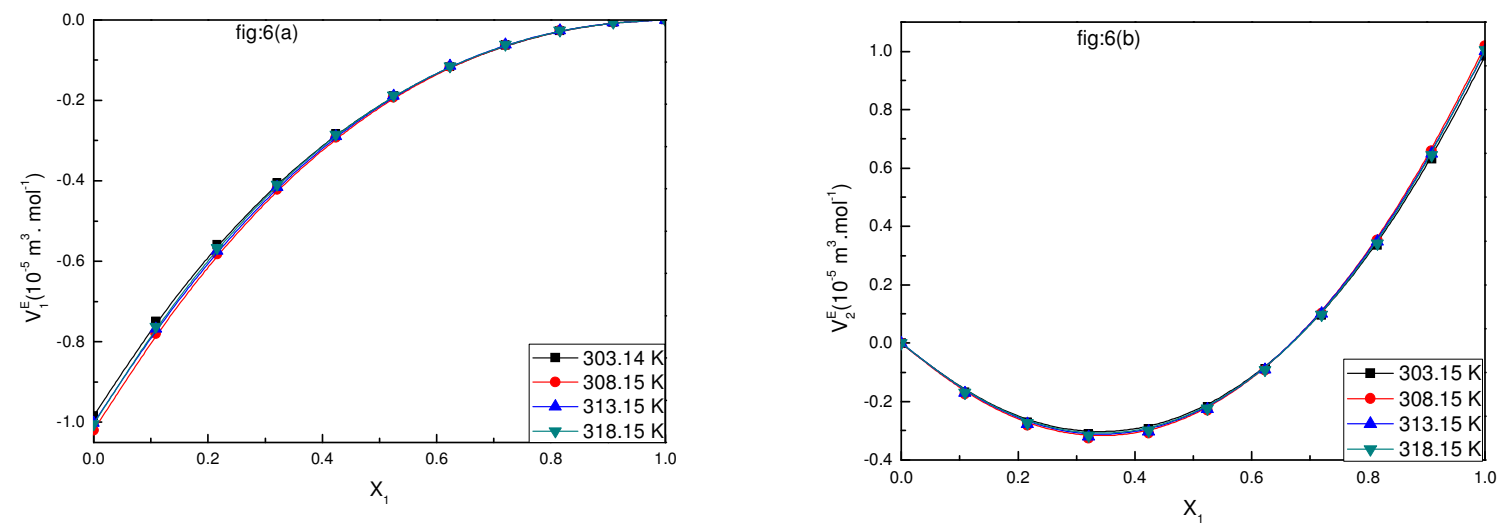

Fig.-6: Variation of Excess Partial Molar Volume $\left(\mathrm{V}_{1}^{\mathrm{E}}\right)$ with Mole Fraction $\left(\mathrm{x}_{1}\right)$ in the Binary Liquid Mixtures of 2MCH with O-CA 6(a), O-TA 6(b) at Various Temperatures.
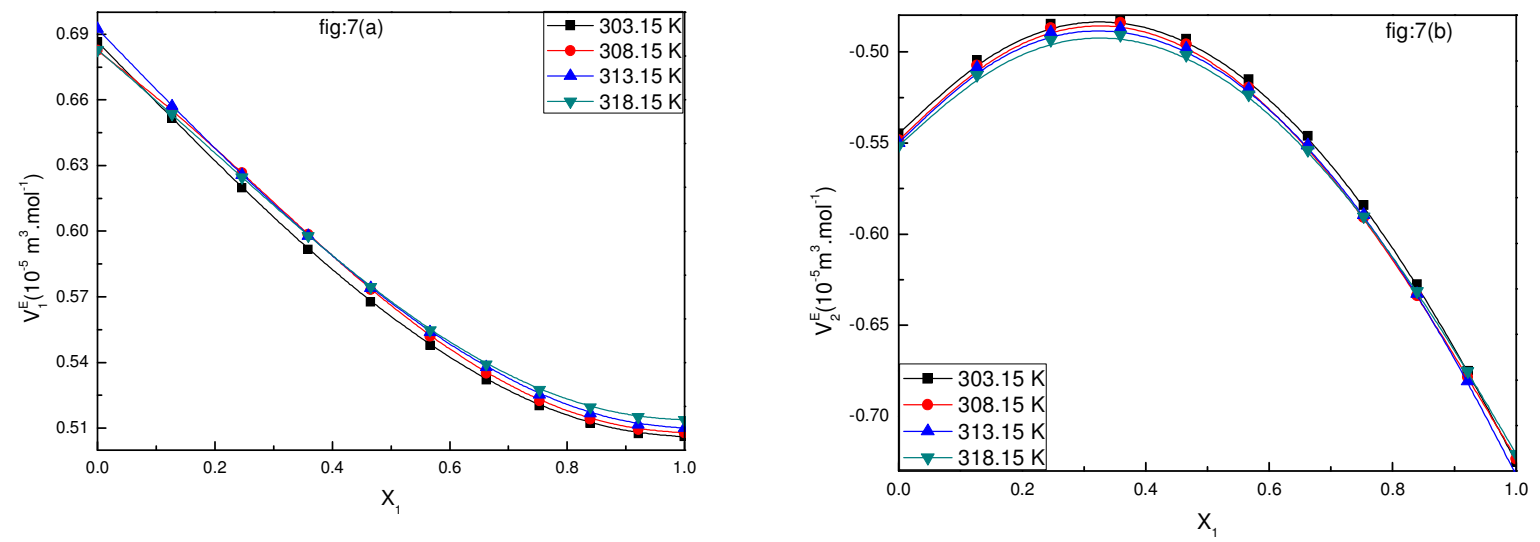

Fig.-7: Variation of Excess Partial Molar Volume $\left(\mathrm{V}_{2}{ }^{\mathrm{E}}\right)$ with Mole Fraction $\left(\mathrm{x}_{1}\right)$ in the Binary Liquid Mixtures of 2-Methylcyclohexanone with O-Chloroaniline7(a), O-Toluidine7(b)

Figures-6a and $\mathrm{b}$ represent the variation of excess partial molar volumes of $V_{m, 1}(2 \mathrm{MCH}), V_{m, 2}$ (amines) in the binary mixtures. Examination of these figures reveals that attractive and weak forces exist between the unlike molecules. These figures support the conclusions drawn from $V^{E}$. The partial molar volumes and excess partial molar volumes of $2 \mathrm{MCH}$ and amines in all the binary liquid mixtures at infinite dilution, $V_{m, 1}^{\infty}, V_{m, 2}^{\infty}, V^{E^{\infty}}{ }_{m, 1}$, and $V^{E}{ }_{m, 2}^{\infty}$, respectively, were obtained by putting $x=0$ in (10) and $x=1$ in (11). Consider,

$$
\begin{gathered}
V^{E, \infty}{ }_{m, 1}=A_{0}+A_{1}+A_{2}+A_{3}+\cdots=V_{m, 1}^{\infty}-V_{1}{ }^{*}, \\
V^{E, \infty}{ }_{m, 2}=A_{0}+A_{1}+A_{2}+A_{3}+\cdots=V_{m, 2}^{\infty}-V_{2}{ }^{*},
\end{gathered}
$$


The pertinent values of $V^{\infty}{ }_{m, 1}, V_{m, 2,}^{\infty} V^{E, \infty}{ }_{m, 1}$ and $V^{E, \infty}{ }_{m, 2}$ are reported in Table-2. From this table, it is seen that these values are negative, from which we conclude that strong interactions exist among the unlike molecules of the liquid mixtures. ${ }^{27}$

\section{CONCLUSION}

Ultrasonic speeds $u$, viscosity, $\eta$ and densities $\rho$, of mixtures of (2-methylcyclohexanone with O-CA, OTA) over the entire composition range have been measured at $T=303.15-318.15 \mathrm{~K}$. The values of $\mathrm{K}_{\mathrm{s}}^{\mathrm{E}}$, $\mathrm{V}^{\mathrm{E}}, \mathrm{L}_{\mathrm{f}}^{\mathrm{E}}, \mathrm{H}^{\mathrm{E}}$ and $\Delta \mathrm{G}^{* \mathrm{E}}$ are calculated from this data. The excess and deviation properties have been fitted to Redlich-Kister type polynomial and corresponding standard deviations have been evaluated. The observed negative values of $\mathrm{K}_{\mathrm{s}}^{\mathrm{E}}, \mathrm{V}^{\mathrm{E}}, \mathrm{L}_{\mathrm{f}}^{\mathrm{E}}, \mathrm{H}^{\mathrm{E}}$ and positive values for all the liquid mixtures studied clearly indicate. The calculated values of partial molar volumes have also been examined. The observed low partial molar volumes in the liquid mixture, when compared to the respective molar volumes of pure components, indicate strong and weak interactions present in the systems.

\section{ACKNOWLEDGMENT}

"Dr.Shaik.Babu wishes to acknowledge the Department of Science and Technology for providing funding through DST-FIST Level-1 Scheme to Department of Physics, KLEF; File No:SR/FST/PS-1/2018/35".

\section{REFERENCES}

1. M. Hasan, D.F. Shirude, A.P. Hiray, A.B. Sawant, U.B. Kadam, Fluid Phase Equilib., 252, 88(2007), DOI:10.1016/j.fluid.2007.01.001.

2. Sk. Suriya Shihab, K. Govinda Rao, M. Gnana Kiran, Shaik. Babu, and S. Sreehari Sastry, Rasayan J. Chem. ,10(1), 59 (2017), DOI: 10.7324/RJC.2017.1011552

3. P.S. Kharat, S.J., Nikam, J. Mol. Liq., 131, 81 (2007), DOI:10.1016/j.molliq.2006.08.053

4. K. Gowrisankar, M., Venkatesulu, A., Srinivasa Krishna, T., Ravindhranath, J. Chem. Thermodyn., 107, 104(2017).

5. K.V. Surya Narayana Raju, S. Salma Begum, B. Dharma Sagar and Shaik. Babu , Rasayan J.Chem., 10(1), 37(2017), DOI: 10.7324/RJC.2017.1011534

6. D. Ubagaramary, I.V.M.V. Enoch, M. Gowrisankar, S. Mullainathan, Russ. J. Phys. Chem., A.92 2665, (2018), DOI:10.1134/s0036024418130319.

7. N. Saini, J.S. Yadav, S.K. Jangra, D. Sharma, V.K. Sharma, J. Chem. Thermodyn., 43, 782(2011), DOI:10.1016/j.jct.2010.12.028.

8. V.K. Yadav Dimple, J.S., Singh, K.C., Sharma, J. Chem. Eng. Data, 54, 2 (2009).

9. V.K. Saini, N., Yadav, J.S., Sunil, K.J., Sharma, D., Sharma, J. Chem. Thermodyn., 43, 782(2011).

10. A.L. Vogel, Text Book of Practical Organic Chemistry, 1989.

11. T.K. Riddick, J.A., Bunger, W.B., Sakano, Organic Solvents, 1986.

12. O. Kiyohara, G.C. Benson, J. Chem. Thermodyn., 11(11), 861(1979), DOI:10.1016/00219614(79)90067-3.

13. G.C. Benson, O. Kiyohara, J. Chem. Thermodyn., 11(11), 1061 (1979), DOI:10.1016/00219614(79)90136-8.

14. G. Douhéret, A. Pal, M.I. Davis, J. Chem. Thermodyn., 22(1), 99(1990), DOI:10.1016/00219614(90)90036-P.

15. O. Redlich, A.T. Kister, Ind. Eng. Chem., 40(2), 345(1948), DOI:10.1021/ie50458a036.

16. S.S. Sastry, S.M. Ibrahim, L.T. Kumar, S. Babu, H.S. Tiong, Int. J. Eng. Res. Technol., 4, 315(2015).

17. K.Govinda Rao, Shaikbabu, Rasayan J. Chem.,12(3), 1110(2019), DOI:10.31788/RJC.2019.1235285

18. T. Kalimulla, G.V. Gangadhara Rao, K. Govinda Rao, S. Babu, Mater. Today Proc., 5, 25850(2018), DOI: $10.1016 /$ j.matpr.2018.06.578.

19. M.W. Fort RJ, Trans. Faraday Soc., 61,2102(1965), DOI:10.1039/tf9656102102

20. H. Iloukhani, N. Zoorasna, R. Soleimani, Phys. Chem. Liq., 43(4), (2005). DOI: $10.1080 / 00319100500134048$.

21. L.J. Garico B, S. Aparico, A. M. Navarro, R.Alcalde, J. Phys. Chem. B., 108,1 (2004).

22. H. Salhi, Shaik.Babu, A.A. Al-Arfaj, M.A. Alkhaldi, N.O. Alzamel, S. Akhtar and N. Ouerfelli, 1917 


\section{RASĀYAN J. Chem.}

Vol. 12 | No. 4 |1909 - 1918| October - December | 2019

Rasayan J. Chem., 9(4), 864(2016).

23. M.N. Pandey Jd, R. D. Rai, R. K. Shukla, A. K. Shukla, Indian J. Pure Appl. Phys., 31, 84(1993).

24. Sk. Suriya Shihab, Shaik. Babu and S.Sreeharisastry, Rasayan J. Chem., 9(4), 641(2016).

25. S. Sreehari Sastry, S. Babu, T. Vishwam, H. Sie Tiong, J. Chem. Thermodyn., 68, 183(2014), DOI: 10.1016/j.jct.2013.09.005.

26. S.V.K. Sastry, S. Babu, H. Sietiong, S.S. Sastry, J. Chem. Pharm. Res., 4, 2122(2012).

27. S. Nayeem, M. Kondaiah, K. Sreekanth, D. K. Rao, Journal of Thermodynamics, Article ID 487403(2014), DOI:10.1155/2014/487403.

[RJC-5481/2019] 